\title{
Review
}

\section{Immunogenicity and safety of SARS-CoV-2 vaccines in clinical trials}

\author{
Hui Xuan Lim ${ }^{1, \dagger}$, Masita Arip ${ }^{2, \dagger}$, Abdul Aziz Al-Fattah Yahaya ${ }^{1}$, Seyed Davoud Jazayeri ${ }^{1,3}$, \\ Sibrandes Poppema ${ }^{4}$, Chit Laa Poh ${ }^{1, *}$ \\ ${ }^{1}$ Centre for Virus and Vaccine Research, School of Medical and Life Sciences, Sunway University, Bandar Sunway, 47500 \\ Subang Jaya, Selangor, Malaysia, ${ }^{2}$ Allergy and Immunology Research Centre, Institute for Medical Research, National \\ Institutes of Health, Ministry of Health Malaysia, Setia Alam, 40170 Shah Alam, Selangor, Malaysia, ${ }^{3}$ Immune \\ Regulation Research Group, School of Biochemistry and Immunology, Trinity Biomedical Sciences Institute, Trinity \\ College Dublin, Dublin, Ireland, ${ }^{4}$ School of Medical and Life Sciences, Sunway University, Bandar Sunway, 47500 \\ Subang Jaya, Selangor, Malaysia
}

\section{TABLE OF CONTENTS}

\section{Abstract}

2. Introduction

3. Inactivated vaccines

3.1 BBIBP-Corv

3.2 New Crown COVID-19

3.3 CoronaVac

4. $m R N A$ vaccines

4.1 mRNA-1273

4.2 BNT162b2

5. Adenovirus vector-based vaccines

5.1 Ad5-vectored COVID-19 vaccine

5.2 Chimpanzee adenovirus-vectored vaccine ChAdOx1 nCoV-19 (AZD1222)

5.3 Adenovirus-vectored vaccines (Sputnik V)

5.4 Ad26.COV2.S

6. Recombinant S protein-based vaccine NVX-CoV2373

7. The promise of COVID-19 vaccines and the emergence of variants

8. Conclusions

9. Author contributions

10. Ethics approval and consent to participate

11. Acknowledgment

12. Funding

13. Conflict of interest

14. References

\section{Abstract}

Severe acute respiratory syndrome coronavirus 2 (SARS-CoV-2) infections were first detected in Wuhan, China in December 2019 and resulted in a worldwide pandemic in 2020. SARS-CoV-2 infections totalled more than 180 million with 3.9 million deaths as of June 24, 2021. Tremendous research efforts have resulted in the development of at least 64 vaccine candidates that have reached Phase I to III clinical trials within 14 months. The primary efficacy endpoint for a random placebo-controlled clinical trial of a COVID-19 vaccine to be approved by US FDA should confer at least 50\% protection against COVID-19. Three COVID-19 vaccines (BNT162b2, mRNA-1273 and Sputnik V) in clinical Phase III trials have now achieved $>90 \%$ efficacy in preventing COVID-19. Since SARSCoV-2 is highly contagious, vaccines are expected to achieve at least $80 \%$ herd immunity in the world's population to effectively prevent SARS-CoV-2 infections. An overview of safety, immunogenicity and efficacy of the current frontrunner vaccines are reviewed. 


\section{Introduction}

Severe acute respiratory syndrome coronavirus 2 (SARS-CoV-2) has caused a global public health crisis. The situation is getting worse as many countries are facing the third wave of SARS-CoV-2 infections and as of 24 June 2021, there were over 180 million infections with 3.9 million deaths globally. There is an urgent need to develop a safe and effective vaccine needed to curtail the escalating COVID-19 pandemic. To date, WHO has reported over 237 vaccine candidates in preclinical and clinical trials using various platforms [1]. Many of the vaccine candidates are in Phase I/II clinical trials to evaluate immunogenicity and safety using different vaccine dosages in a small number of healthy volunteers. Some of these vaccine candidates have progressed to Phase III trials to further demonstrate efficacy and safety in larger cohorts of participants. As of May 20, 100 vaccine candidates have entered clinical evaluations and 20 vaccines have progressed to Phase III clinical trials. Several of the forerunners have completed Phase III trials and have been approved for regular use in some countries and emergency use in others.

The pandemic has warranted urgent actions to develop vaccines at warp speed. The mortality rate among individuals with underlying medical conditions and old age is higher than those who are young and healthy [2]. Besides conventional vaccines such as inactivated and recombinant subunit proteins, mRNA vaccines which have never been approved in the history of human vaccinations have now been used to vaccinate millions of people. However, the long-term safety and efficacy in preventing COVID-19 infections are still unclear.

Vaccine development is a rigorous and complex process. Vaccine safety is the primary goal of COVID19 vaccine development, which can be evaluated in various animal models before human clinical trials. The incidence of solicited local and systemic adverse events as well as the usage of pain medication for 7 days after each injection, unsolicited adverse reactions for 28 days following each injection must be taken into account in the safety assessment of vaccine candidates. Solicited local adverse events included pain, redness, swelling and induration at the injection site while solicited systemic adverse events included fever, headache, fatigue, nausea, muscle ache and joint pain. In terms of severity, adverse events were classified as mild (transient discomfort for $<48 \mathrm{~h}$ ), moderate (mild limitation in activity) or severe (medical intervention required) or life-threatening. Safety of the vaccines should be monitored over a longer-term period of more than 2 years after vaccination. For example, medically attended and severe adverse events in patients vaccinated with Moderna mRNA-1273 vaccine will be assessed for 2 years in Phase III clinical trials [3].

Antibody-dependent enhancement (ADE) and vaccine-associated enhanced respiratory disease (VAERD) are two potential risks related to vaccine-enhanced COVID19 disease. ADE usually arises when viruses bind to nonneutralizing antibodies which in turn facilitate viruses to enter the host cells via Fc receptors expressed on monocytes. ADE could also occur when antibodies induced by vaccines were insufficient in neutralizing the virus. ADE has been observed in SARS-CoV-1 and MERS-CoV infections where anti-S antibodies were involved in ADE of SARS infections by gaining entry into FcR-expressing cells [4], while a neutralizing antibody (Mersmab 1) targeting the receptor-binding domain (RBD) aided the entry of MERS pseudo-virus via the DPP4 pathway [5]. In view of ADE caused by using the whole $S$ protein or inactivated vaccine of SARS-CoV-1 and MERS-CoV, researchers have removed the potential ADE-promoting epitopes from the $S$ protein by using the RBD as a sub-unit vaccine [6]. Despite the knowledge that ADE was caused by the whole $S$ protein in SARS-CoV-1, the majority of the SARS-CoV-2 vaccine candidates employed the whole $S$ protein as an immunogen. The SARS-CoV-2 receptor-binding domain (RBD) has also been shown to elicit a potent neutralizing response without ADE $[7,8]$.

VAERD could occurs when Th2 cytokines such as IL-4, IL-5 and IL-13 were overproduced, resulting in excessive mucus production, increased polymorphonuclear leukocytes and eosinophils in lung histopathology [9]. It has been suggested that non-neutralizing antibodies could stimulate Th2 response, leading to the formation of immune complexes which could cause tissue damage [10]. SARS-CoV vaccines based on the inactivated virus or recombinant $\mathrm{S}$ or $\mathrm{N}$ proteins administered with and without adjuvants in mice, ferrets and non-human primates were reported to induce Th2-mediated immunopathology with eosinophil infiltrations after challenge [11, 12]. In addition, inactivated MERS-CoV vaccine was found to increase infiltrations of eosinophil by promoting the production of Th2 cytokines, resulting in adverse lung pathology in mice [13]. Most of the vaccine candidates that entered Phase III clinical trials were designed to elicit S protein-mediated immune responses. However, earlier studies have shown that whole inactivated virus or the entire $\mathrm{S}$ glycoprotein from SARS-CoV-1 were associated with increased respiratory conditions in animal models $[12,14]$. Therefore, preventing Th2-biased immunity or eliminating elicitation of poorly neutralizing antibodies would be paramount to ensuring vaccine safety. Immunogenicity data of Th1 vs. Th2 polarization in addition to neutralization antibodies vs total IgG responses in animal models could provide a critical framework for safety assessment and regulatory decisions required to accelerate vaccine development. Characterization of the types of immune responses induced by COVID19 vaccine candidates in animal challenge studies could be useful to evaluate the possibility of the vaccine in inducing vaccine-associated ERD in humans. FDA has included the requirement to demonstrate the Th1/Th2 ratio of cellular 
immune responses elicited by vaccine candidates in clinical trials [15].

Vaccines fundamentally activate the immune system of an individual to prepare for possible infection by a virus, so the immune response mounted would be enhanced. To study their usefulness, the vaccine candidates would have to be assessed for their immunogenicity and safety in clinical trials. Immunogenicity is the ability of an antigen present in a vaccine to elicit measurable immune responses. The adaptive immune responses were activated after viral uptake and antigen processing by antigen-presenting cells. $\mathrm{B}$ cells are activated by the antigens through the $\mathrm{B}$ cell receptor (BCR). B cells are assisted by activated T follicular helper cells (Tfh) to differentiate into plasma cells which can then produce specific antibodies against the antigen. Humoral immune responses to SARS-CoV-2 were mainly mediated by antibodies that were directed to the spike glycoprotein and the nucleocapsid protein. However, neutralizing antibodies are targeted mainly at the SARS-CoV-2 spike protein [16]. Neutralizing antibodies should be effectively preventing viruses from entering host cells to limit the infection and they also play an important protective role to prevent re-infection.

By contrast, the cellular immune response is mediated by $\mathrm{T}$ cells. Cytotoxic and helper $\mathrm{T}$ cells are known to play a crucial role in adaptive immune responses by clearing the virus-infected cells [17]. CD8+ T cells activated by peptide antigens presented on MHC I differentiate into the cytolytic $\mathrm{T}$ cells, whereas CD4+ T cells activated by peptide antigens presented on MHC II further enhances CD8+ T cell responses. T-helper 1 (Th1), T-helper 2 (Th2), Thelper 17 (Th17) and regulatory T cells (Treg) are effector subtypes of activated CD4+ T helper cells that play important roles in mediating immune response through the release of various cytokines. Th1 cells secrete IFN- $\gamma$ as their signature cytokine to activate macrophages and DCs. Th1 cells also secrete TNF- $\alpha$, IL-2 and lymphotoxin. By contrast, Th2 cells do not produce IFN- $\gamma$ but secrete cytokines such as IL-4, IL-5, and IL-13. Both Th1 and Th2 cells support the production of $\mathrm{B}$ cell antibodies and induction of immunoglobulin class-switching [18]. Th17 cells are primarily responsible for the production of cytokines such as IL-17A, IL-17F, IL-21 and IL-22. Tfh cell can also secret IL-21 [19]. Th17 cells play a crucial role as evident by their presence in the biopsy of patients who suffered lung infections due to COVID-19 [20]. The total number of CD4+ T cells, CD8+ T cells, B cells and natural killer cells is significantly related to the inflammatory status in COVID-19 patients, especially the CD8+ T cells and CD4+/CD8+ ratio [21]. Regulatory T cells (Treg) have been shown to regulate inflammation in other coronavirus infections but have an unknown-role in SARS-CoV-2 immunopathology [22]. Infection with SARS-CoV-1 reported persistence of T cells which provided long term virus-specific $\mathrm{T}$ cell immunity. The presence of memory $\mathrm{T}$ cell responses up to 11 years post-infection was reported in convalescent patients from SARS-CoV-1 infection [23]. Intriguingly, some SARSCoV-2 patients were found to develop specific memory $\mathrm{T}$ cells but specific antibodies were absent. This indicated that there is a probability of cellular immune responses in the absence of humoral response. However, the persistence of memory T cells in SARS-CoV-2 infection is still unknown [24, 25].

The advantages and disadvantages of SARS-CoV2 vaccine candidates are presented in Table 1 . The safety of the SARS-CoV-2 vaccine candidates and their immunogenicity in eliciting neutralizing antibodies will be presented in Table 2 (Ref. [3, 26-40]). The findings on T cell responses and cytokine profiles elicited by SARS-CoV2 vaccine candidates are addressed in Table 3 (Ref. [26$31,41])$. The emergence of SARS-CoV-2 variants and their impacts on the efficacies of current vaccines against SARSCo-V-2 are discussed.

\section{Inactivated vaccines}

\subsection{BBIBP-Corv}

The inactivated vaccine platform is the most common vaccine platform used in vaccinology. Many infectious diseases have already been eradicated using inactivated vaccines and it would be desirable to utilize the much tried and tested platform for developing a safe SARS$\mathrm{CoV}-2$ vaccine. The inactivated vaccine, BBIBP-Corv, developed by Chinese pharmaceutical company Sinopharm, was produced from the 19nCoV-CDC-Tan-HB (02) (HB02) strain derived from the throat swab of a covid-19 patient [42]. It showed high homology with many SARS-CoV-2 strains and therefore displayed a high level of phylogenetic relationships with strains within the SARS-CoV-2 population [32]. The logic behind the development of this vaccine is that inactivated vaccine platforms already had a good track record to provide immune protection against respiratory diseases [43]. Research has been going at an accelerated pace due to the scale of the pandemic, leading to changes from typical human trial protocols as Phase I and II trials were reportedly conducted in parallel [9].

The results of both Phase I $(\mathrm{n}=192)$ and II $(\mathrm{n}=$ 448) trials showed that the BBIBP-CorV vaccine was safe and well-tolerated at $4 \mu \mathrm{g}$ and $8 \mu \mathrm{g}$ doses with aluminum hydroxide as the adjuvant via intramuscular injections in the young adult and elderly groups (18-59 years and $\geq 60$ years). Only mild adverse events were observed. Injection site pain or fever was observed in $29 \%$ of 144 vaccinees in the Phase I trial, while $23 \%$ of 336 vaccinees in the Phase II trial had at least one adverse event within one week after vaccination [32]. Laboratory measurements found no clinically significant abnormalities linked to the vaccines which indicated good tolerability in healthy individuals. 


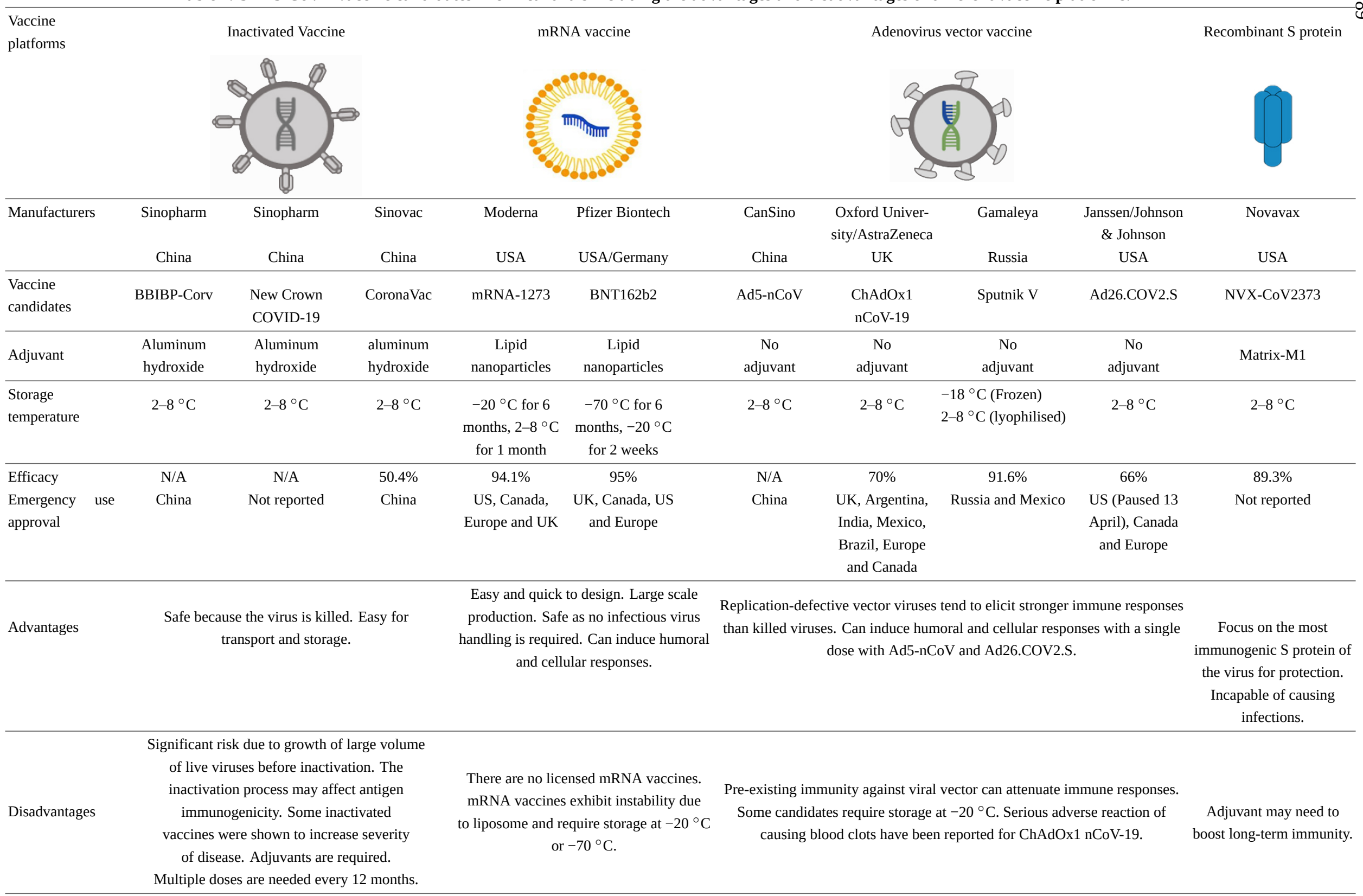


Table 2. Neutralizing antibody responses and safety of COVID-19 vaccine candidates.

\begin{tabular}{|c|c|c|c|c|c|c|c|c|c|}
\hline Vaccine candidates & Clinical trials & No. of subjects & Route & No. of doses & s Schedule (Days) & Dosage & Immunogenicity (GMT NtAb) & Safety & References \\
\hline \multirow{9}{*}{$\begin{array}{l}\text { Inactivated vaccine } \\
\text { (BBIBP-CorV) }\end{array}$} & Phase I & 192 (18-59 years) & I.M & 2 & Days-0, 28 & $2 \mu g$ & (Day-42) 87.7 & \multirow{6}{*}{$\begin{array}{l}\text { Fever was reported in less than } 10 \% \text { of } \\
\text { participants. All adverse reactions were } \\
\text { - mild. No severe adverse reaction was } \\
\text { reported within } 28 \text { days post-vaccination } \\
\text { in all groups. }\end{array}$} & \multirow{9}{*}{ [32] } \\
\hline & & & & & & $4 \mu g$ & 211.2 & & \\
\hline & & & & & & $8 \mu \mathrm{g}$ & 228.7 & & \\
\hline & Phase I & ( $>60$ years) & I.M & 2 & Days-0, 28 & $2 \mu \mathrm{g}$ & (Day-42) 80.7 & & \\
\hline & & & & & & $4 \mu \mathrm{g}$ & 131.5 & & \\
\hline & & & & & & $8 \mu \mathrm{g}$ & 170.8 & & \\
\hline & \multirow[t]{3}{*}{ Phase II } & \multirow[t]{3}{*}{448 (18-59 years) } & I.M & 2 & Days-0,14 & $4 \mu g$ & (Day-28) 169.5 & \multirow{3}{*}{$\begin{array}{l}\text { Adverse effects reported were mild or moder- } \\
\text { ate. Fever in less than } 4 \% \text { of participants in } \\
\text { each dosage group. }\end{array}$} & \\
\hline & & & & & Days-0, 28 & $4 \mu g$ & 218.0 & & \\
\hline & & & I.M & 1 & Day-0 & $8 \mu g$ & (Day-28) 14.7 & & \\
\hline \multirow{5}{*}{$\begin{array}{l}\text { Inactivated vaccine } \\
\text { (New Crown COVID-19) }\end{array}$} & Phase I & 96 (18-59 years) & I.M & 3 & Days-0, 28, 56 & $2.5 \mu \mathrm{g}$ & (Day-70) 316 & \multirow{5}{*}{$\begin{array}{l}\text { All adverse reactions were mild (grade } 1 \text { or } 2 \text { ), } \\
\text { mainly injection site pain and fever. No other } \\
\text {-adverse reactions were reported within } 28 \text { days } \\
\text { post-vaccination. }\end{array}$} & \multirow{5}{*}{ S [33] } \\
\hline & & & & & & $5 \mu \mathrm{g}$ & 206 & & \\
\hline & & & & & & $10 \mu \mathrm{g}$ & 297 & & \\
\hline & Phase II & 224 (18-59 years) & I.M & 2 & Days-0, 14 & $5 \mu g$ & (Day-28) 121 & & \\
\hline & & & & & Days-0, 21 & $5 \mu \mathrm{g}$ & (Day-35) 247 & & \\
\hline \multirow{7}{*}{$\begin{array}{l}\text { Inactivated vaccine } \\
\text { (CoronaVac) }\end{array}$} & Phase I & 144 (18-59 years) & I.M & 2 & Days-0, 14 & $3 \mu \mathrm{g}$ & (Day-42) 5.4 & \multirow{7}{*}{$\begin{array}{l}\text { Most adverse reactions were mild (grade } 1 \text { ). } \\
\text { The most commonly reported symptom was } \\
\text { pain at the injection site. No serious adverse } \\
\text { events were noted within } 28 \text { days of vaccinatior }\end{array}$} & \multirow{7}{*}{ [34] } \\
\hline & & & & & Days-0, 28 & $3 \mu g$ & (Day-56) 19.0 & & \\
\hline & & & & & & $6 \mu \mathrm{g}$ & 29.6 & & \\
\hline & Phase II & 600 (18-59 years) & I.M & 2 & Days-0, 14 & $3 \mu \mathrm{g}$ & (Day-42) 23.8 & & \\
\hline & & & & & & $6 \mu \mathrm{g}$ & 30.1 & & \\
\hline & & & I.M & 2 & Days-0, 28 & $3 \mu \mathrm{g}$ & (Day-56) 44.1 & & \\
\hline & & & & & & $6 \mu \mathrm{g}$ & 65.4 & & \\
\hline
\end{tabular}


Table 2. Continued.

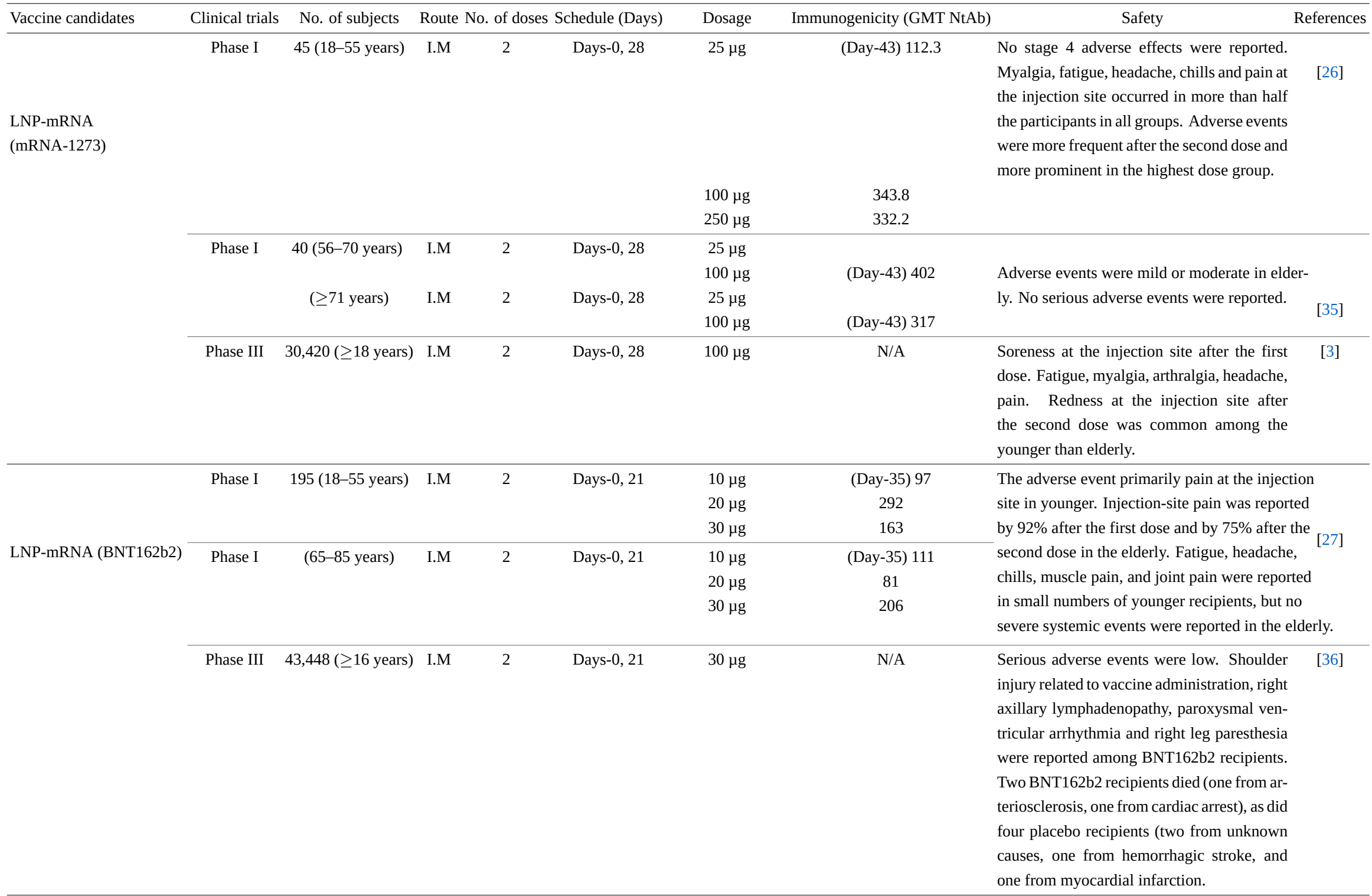


Table 2. Continued.

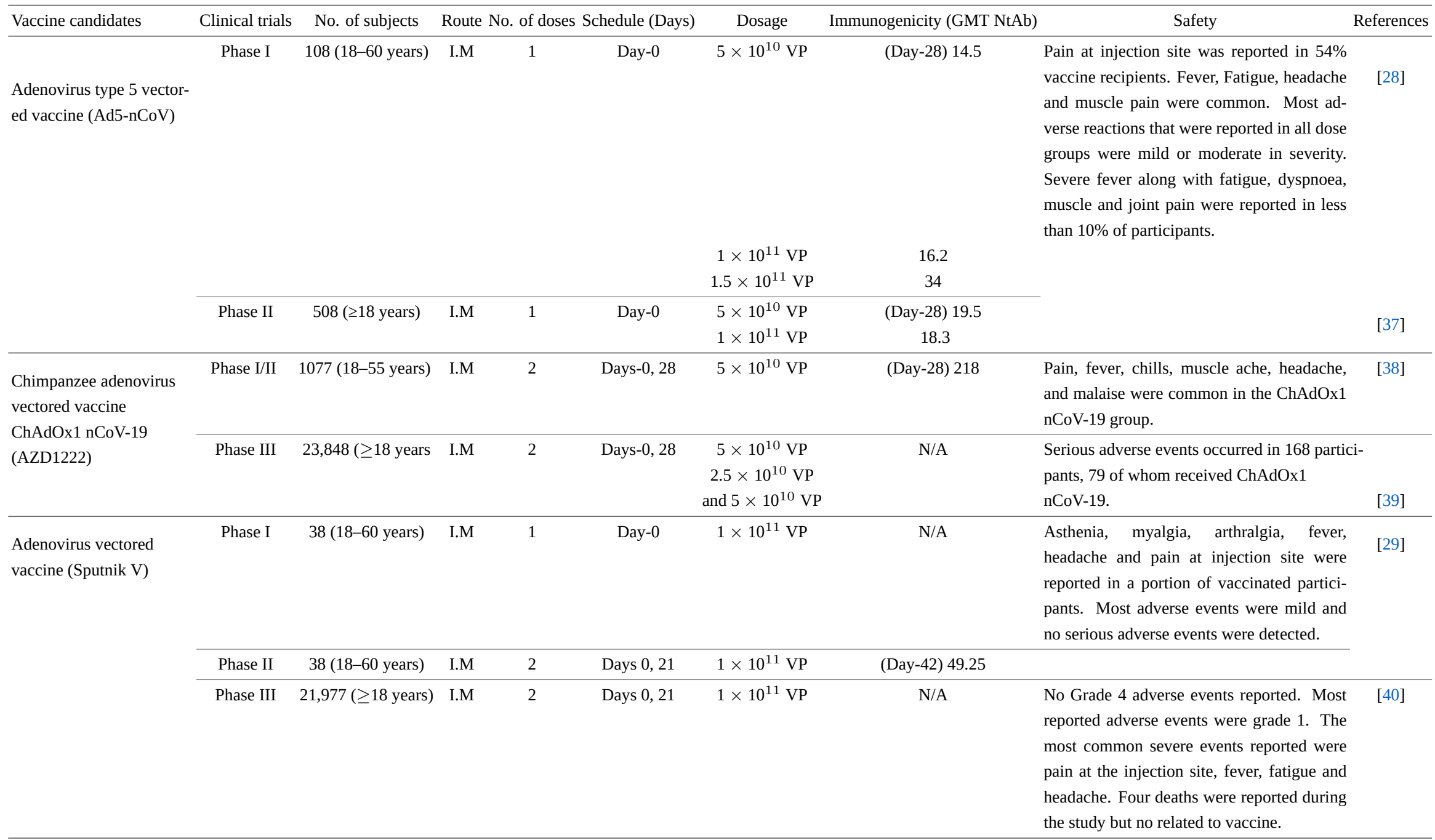


Table 2. Continued.

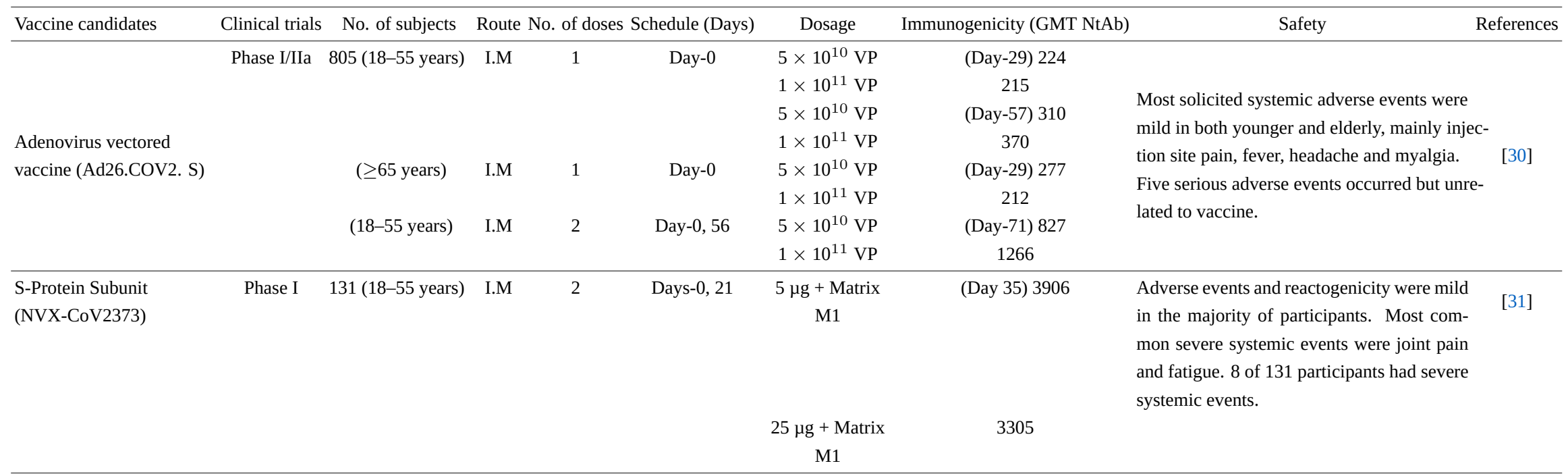

N/A denotes no data available; I.M denotes intramuscular administration; VP denotes viral particles. 
Table 3. T cell responses and cytokine profiles of COVID-19 vaccine candidates.

\begin{tabular}{|c|c|c|c|c|}
\hline Vaccine candidates & $\mathrm{T}$ cell responses & Th1 cytokines & Th2 cytokines & References \\
\hline Inactivated vaccine (BBIBP-CorV) & N/A & N/A & N/A & N/A \\
\hline Inactivated vaccine (New Crown COVID-19) & N/A & N/A & N/A & N/A \\
\hline Inactivated vaccine (CoronaVac) & N/A & N/A & N/A & N/A \\
\hline LNP-mRNA (mRNA-1273) & $\begin{array}{c}\text { Good CD4+ T cells } \\
\text { Low levels of CD8+ T cells }\end{array}$ & IFN- $\gamma$, IL-2, TNF- $\alpha$, & Minimal IL-4, IL-13 & [26] \\
\hline LNP-mRNA (BNT162b2) & Good CD4+ and CD8+ T cells & IFN- $\gamma$, IL-2 & Minimal IL-4 & [27] \\
\hline Adenovirus type 5 vectored vaccine (Ad5-nCoV) & Detected CD4+ and CD8+ T cells & IFN- $\gamma$, IL-2, TNF- $\alpha$ & N/A & [28] \\
\hline $\begin{array}{l}\text { Chimpanzee adenovirus vectored vaccine } \\
\text { ChAdOx1 nCoV-19 (AZD1222) }\end{array}$ & Detected CD4+ and CD8+ T cells & IFN- $\gamma$, IL-2, TNF- $\alpha$ & Minimal IL-4, IL-5, IL-13 & [41] \\
\hline Adenovirus vectored vaccine (Sputnik V) & Detected CD4+ and CD8+ T cells & IFN- $\gamma$ & N/A & [29] \\
\hline Adenovirus vectored vaccine (Ad26.COV2. S) & Detected CD4+ and CD8+ T cells & IFN- $\gamma$, IL-2 & Minimal IL-4, IL-13 & {$[30]$} \\
\hline S-Protein Subunit (NVX-CoV2373) & Detected CD4+ T cells & IFN- $\gamma$, IL-2, TNF- $\alpha$ & Minimal IL-5, IL-13 & [31] \\
\hline
\end{tabular}

Good immunogenicity of the vaccine was demonstrated as the vaccine could induce rapid humoral responses and $100 \%$ seroconversion was evident in both cohorts by day 42. The two-dose immunizations with $4 \mu \mathrm{g}$ dose on days 0 and 21 or days 0 and 28 in Phase II were found to elicit higher levels of neutralizing antibodies at 282.7 (95\% CI, 221.2-361.4) and 218.0 (95\% CI, 181.8-261.3), respectively; when compared to the single $8 \mu \mathrm{g}$ dose with a GMT of 14.7 (95\% CI, 11.6-18.8) on day 28 or the $4 \mu \mathrm{g}$ dose on days 0 and 14 . No cellular immune responses to the inactivated BBIBP-Corv were reported.

Due to the lack of clinical data for children and adolescents, studies on the effects of the vaccine in these groups are currently on-going [42]. Phase III trials officially began in July 2020 in China as well as in countries such as Argentina (NCT04560881) and the UAE (ChiCTR2000034780). Phase III trials were expected to conclude by late 2021 to provide further information on the dosages and immunization schedules as well as safety and immunogenicity. The World Health Organization (WHO) has granted emergency approval for BBIBP-Corv on May 7, 2021 [44].

\subsection{New Crown COVID-19}

New Crown COVID-19 is an inactivated vaccine produced by Sinopharm. The SARS-CoV-2 virus (WIV04 strain; GenBank accession number MN996528) was cultivated in Vero cells and it was inactivated with $\beta$ propiolactone. In the phase I trial, 96 participants (18-59 years) were assigned to receive the inactivated vaccine with aluminum hydroxide as the adjuvant via intramuscular injections in a three-dose schedule at $2.5 \mu \mathrm{g}, 5 \mu \mathrm{g}$ and 10 $\mu \mathrm{g} /$ dose on days 0,28 and 56 . The primary immunogenicity outcome showed good neutralizing antibody response 14 days after 3 doses of vaccinations. All participants receiving either low $(2.5 \mu \mathrm{g})$ or high (10 $\mu \mathrm{g})$ dose showed 100\% seroconversion while medium (5 $\mu$ g) dose group achieved seroconversion at $95.8 \%$. After the third dose, GMT of neutralizing antibody at day 14 was found to be 316 (95\%
CI, 218-457), 206 (95\% CI, 123-343) and 297 (95\% CI, 208-424) for low, medium and high dose, respectively (Table 1). The neutralizing antibody titers were comparable with the levels in other published results from mRNA-1273 and BNT162b1 mRNA vaccines [26] and higher than the titers in convalescent human sera. In the Phase II trial, 224 participants were randomly divided into 2 schedule groups (days 0 and 14, and days 0 and 21) using $5 \mu \mathrm{g}$ dose. The seroconversion rate of neutralizing antibodies reached $97.6 \%$ in those receiving two middle-dose injections at 14-and 21day. The GMT was 121 (95\% CI, 95-154) in the group receiving injections on days 0 and 14 and 247 (95\% CI, 176-345) in the group of participants receiving $5 \mu \mathrm{g}$ injections on days 0 and 21 [33]. However, there was no assessment of CD4+ and CD8+ T cell responses, including the Th1 and Th2 responses which were characterized by IFN- $\gamma$ and IL-4 cytokines, respectively. The inactivated vaccine was reported to elicit robust antibody responses in participants from 18-59 years of age but did not include participants $\geq 60$ years of age. Vaccine candidates developed by Sinopharm could be stored at normal fridge temperatures of $2{ }^{\circ} \mathrm{C}$ to $8{ }^{\circ} \mathrm{C}$. Phase III clinical trial has begun on September 2020 for longer-term assessment of safety, efficacy and immune persistence with testing two dosages given 21 days apart (NCT04612972). The study is estimated to complete on December 2021.

\subsection{CoronaVac}

CoronaVac was developed by Sinovac Life Sciences Co., Ltd (Beijing, China) and is an inactivated SARSCoV-2 vaccine with aluminum hydroxide as an adjuvant. The SARS-CoV-2 virus was propagated in Vero cells and harvested viruses were inactivated by $\beta$-propiolactone before further purification by chromatography. The vaccine CN2 strain was derived from the bronchoalveolar lavage fluid of a SARS-CoV-2 patient from China [45].

For the inactivated SARS-CoV-2 vaccine, CoronaVac, 744 healthy participants aged 18-59 years in Phase I/II trials were included to evaluate immunogenicity, safety 
and tolerance. The trials were randomized, double-blind and placebo-controlled, with established safety and immunogenic assessment criteria.

No significant differences in the incidence of adverse reactions was reported among the three groups of participants receiving a low dose of $3 \mu \mathrm{g}$, a high dose of 6 $\mu \mathrm{g}$ or placebo for both vaccination schedules (0,14 days and 0, 28 days) in the Phase II trials. Most of the adverse reactions were mild and no severe vaccine-related adverse events were reported within 28 days of vaccination except for one case of acute hypersensitivity with urticaria being reported in the day 0 and 14 cohort but the participant recovered and continued with the trial. Thus, there are no dose-related safety concerns. The mild adverse events were injection-site pain or fever (10\% to $11 \%$ of 120 participants) in participants receiving for both the low and high doses and most adverse events were resolved within $48 \mathrm{~h}$.

Phase II trials showed increased immune responses when compared to Phase I with over $90 \%$ seroconversions for the participants receiving the $3 \mu \mathrm{g}$ and $6 \mu \mathrm{g}$ doses. Cohorts from days 0 and 14 reported 92\% (3 $\mu \mathrm{g})$ and $98 \%(6 \mu \mathrm{g})$ seroconversion when compared to placebo group that showed $3 \%$ on day 14 . The seroconversion rates of RBD-specific IgG were $97 \%$ in the $3 \mu$ g group, $100 \%$ in the $6 \mu \mathrm{g}$ group and $0 \%$ in the placebo group at day 21 [34]. Thus, administration of two doses of Coronavac vaccines at $3 \mu \mathrm{g} /$ dose at days 0 and 28 was suitable for assessment of efficacy for future Phase III trials. T cell mediated immunity was not assessed in the Phase II trial. The clinical trial did not include elderly $\geq 60$ years of age or those with co-morbidities.

Four Phase III trials are ongoing in Brazil (NCT04456595), Indonesia (NCT04508075), Turkey (NCT04582344) and Chile (NCT04651790). Interim results released by Sinovac showed that initial vaccine efficacy was at $78 \%$ but variable efficacies were reported for the Phase III trials in the three countries. Vaccine efficacy at $91.25 \%$ was reported in Turkey and $65.3 \%$ in Indonesia but Brazil reported a reduced efficacy at only $50.4 \%$ [46].

\section{4. mRNA vaccines}

\section{1 mRNA-1273}

mRNA vaccines provide flexibility in the design and expression of viral antigens that are similar to those expressed during natural infections. The mRNA vaccine platform has the potential to facilitate rapid vaccine development in response to emerging pathogens. mRNA vaccine comprises a mRNA strand coding for a target antigen which is translated in the cytoplasm of the host cell [47]. mRNA1273 is a vaccine that carries mRNA of the full-length spike protein encapsulated in lipid nanoparticles and is developed by Moderna and National Institute of Allergy and Infectious
Diseases (NIAID). It encodes the SARS-CoV-2 spike protein antigen which is a stable prefusion SARS-CoV-2 glycoprotein with intact S1 and S2 cleavage sites. S-2P is stabilized by two consecutive proline substitutions at amino acids 986 and 987, which are located at the top of the central helix in the S2 subunit [48].

In the Phase I dose-escalation clinical trial, 15 participants (18-55 years of age) were administered with two doses of either $25 \mu \mathrm{g}, 100 \mu \mathrm{g}$ or $250 \mu \mathrm{g}$ of vaccine at 4 weeks apart. The two-dose mRNA-1273 vaccine was generally safe and well-tolerated when tested across the three dosages in 45 healthy adults. Participants who were administered with $250 \mu$ g antigens, reported having more systemic effects after their second dose. Out of fourteen participants, 13 experienced one or more severe events. After the second vaccination, participants receiving the $25 \mu \mathrm{g}$ dose showed the lowest neutralizing responses while those receiving higher doses at $100 \mu \mathrm{g}$ and $250 \mu \mathrm{g}$ groups exhibited higher responses of geometric mean ID 543.8 (95\% CI, 261.2 to 452.7) and 332.2 (95\% CI, 266.3 to 414.5), respectively at day 43 . The immune response to $100 \mu \mathrm{g} /$ dose showed 2.1-fold higher than those observed in 38 convalescent sera after the second vaccination. T cell responses were also evaluated in humans at the $25 \mu \mathrm{g}$ and $100 \mu \mathrm{g}$ dose levels. On stimulation by S-specific peptides, expression was high towards Th1 cytokines (TNF- $\alpha>$ Il-2 $>$ IFN- $\gamma$ ) and without significant elevation of type 2 helper T cell (Th2) cytokine expression (IL-4 and IL-13). Low levels of CD8+ $\mathrm{T}$ cell responses were observed in the participants (18-55 years of age) at $100 \mu \mathrm{g} /$ dose [26].

The clinical trials of mRNA-1273 were expanded to include 40 older adults (56 to 70 years or $\geq 71$ years) due to the higher morbidity and mortality of COVID-19 in elderly adults. The participants were administered with two doses of either $25 \mu \mathrm{g}$ or $100 \mu \mathrm{g}$ at 28 days apart. The vaccine was proven safe as only mild and moderate adverse events were reported in older adults [35]. At day 43 (14 days after the second dose of vaccine), GMTs of neutralizing-antibody elicited by the $100 \mu$ g dose were 402 (95\% CI, 289-560) and 317 (95\% CI, 198-508) for participants aged 56 to 70 years and 71 years of age or older, respectively. The $100 \mu \mathrm{g}$ dose yielded increased binding and neutralizing titers when compared to the $25 \mu \mathrm{g}$ dose. Phase III study enrolled 30,420 participants 18 years of age or older, of whom 15,210 received the vaccine while 15,210 received the placebo. The mRNA-1273 vaccine administered at $100 \mu \mathrm{g}$ demonstrated $94.1 \%$ efficacy at preventing severe COVID-19 infections. Moderate transient reactogenicity after vaccination did occur but no safety concerns were identified in the Phase III trial (NCT04470427) [3].

\subsection{BNT162b2}

Four mRNA-based vaccine candidates, BNT162a1, BNT162b1, BNT162b2 and BNT162c2 representing two different antigens: $\mathrm{RBD}$ or full-length 
spike (with 2 proline mutations) were developed by of Pfizer and BioNTech (Germany). BNT162a1 is an uridine-containing mRNA encoding the RBD while BNT162c2 is self-amplifying mRNA carrying a modified spike protein [49]. BNT162b1 and BNT162b2 are both nucleoside-modified RNAs formulated in lipid nanoparticles. BNT162b2 encoded the stabilized prefusion SARSCoV-2 full-length spike protein, modified by 2 proline mutations (P2 S) which locked it in the prefusion conformation whilst BNT162b1 encoded the RBD [48, 50]. The safety and immunogenicity of three different doses (10 $\mu \mathrm{g}, 20 \mu \mathrm{g}$, or $30 \mu \mathrm{g}$ ) of BNT162b1 and BNT162b2 were evaluated in 195 adults aged 18 to 55 years and 65 to 85 years. The two vaccination candidates elicited similar or higher geometric mean titers (GMTs) than convalescent sera in both younger and older adults, in a dose-dependent manner [27]. After a two-dose schedule of $30 \mu \mathrm{g}, \mathrm{BNT} 162 \mathrm{~b} 1$ or BNT162b2 was found to elicit SARS-CoV-2 neutralizing antibodies with GMTs ranging from 1.1 to 2.2 times the GMTs of convalescent serum panel in the 65-85-year-old participants and from 1.7 to 4.6 times the GMTs of convalescent serum panel in the 18-55-year-old cohort [27]. Thus, it can be concluded that both vaccines elicited lower neutralizing responses in the older than the younger participants. For cellular immune responses, BNT162b2 elicited S-specific CD8+ T cells and CD4+ Th1 cells with high expressions of IFN- $\gamma$ and IL-2. Low levels of IL-4 were detected, indicating a Th1 profile with a minimal risk of Th2-associated VAERD [51].

BNT162b2 was reported to have milder severity of systemic reactions (fatigue, headache, chills, muscle ache, and joint pain) than BNT162b1, particularly in older adults [27]. Therefore, the BNT162b2 vaccine candidate was chosen to progress to the Phase II/III study at $30 \mu \mathrm{g}$ dose level in a two-dose schedule (21 days apart), based on the data from preclinical and Phase I clinical investigation. Phase III study enrolled 43,448 participants (16 years of age or older) who were healthy or had chronic diseases such as hepatitis B, hepatitis C or HIV infections. BNT162b2 vaccine was administered to 21,720 participants while 21,728 received the placebo. BNT162b2 was able to prevent COVID-19 infections in 95\% of vaccine recipients aged 16 years or older and no serious safety concerns were observed (NCT04368728) [36]. mRNA-based vaccines appear to be an attractive alternative to conventional vaccines due to low-cost manufacturing processes which were rapid and scalable. However, the BNT162b2 mRNA vaccine would need to be stored at $-70{ }^{\circ} \mathrm{C}$ with a shelf life of about 6 months as liposomes were unstable at room temperate. Freezers with the capacity to hold large volumes of vaccines at this temperature would be needed. This stringent requirement of storage at $-70{ }^{\circ} \mathrm{C}$ is a limitation for BNT162b2 from Pfizer compared with Moderna mRNA1273 vaccine which was reported to be stable at the refrigerated temperature of $2{ }^{\circ} \mathrm{C}$ to $8{ }^{\circ} \mathrm{C}$ for up to 30 days with a 6-month shelf life. Recently, it has been reported that storage for the Pfizer mRNA vaccine at $-20^{\circ} \mathrm{C}$ was feasible for up to 2 weeks and it might improve distributions in underdeveloped countries [52].

\section{Adenovirus vector-based vaccines}

\subsection{Ad5-vectored COVID-19 vaccine}

Ad5-nCoV is a recombinant adenovirus serotype type 5 vectored vaccine encoding the full-length SARSCoV-2 WT spike protein. It was developed by CanSino Biologics Inc., China.

Healthy adults $(n=108)$ aged 18 to 60 years were enrolled in a Phase I clinical trial and they received a single dose of vaccine consisting of either $5 \times 10^{10}, 1 \times 10^{11}$, and $1.5 \times 10^{11}$ virus particles (VP) intramuscularly. The Ad5$\mathrm{nCoV}$ vaccine was shown to be immunogenic as significant levels of neutralizing antibodies were detected at day 14 and peaked at day 28 post-vaccination. Besides, specific T cell responses were generated from day 14 post-infection. Participants receiving the high dose of $1.5 \times 10^{11} \mathrm{VP}$ were found to present severe fever, fatigue, muscle pain, or joint pain. Therefore, the low dose $\left(5 \times 10^{10}\right.$ viral particles $)$ and middle dose $\left(1 \times 10^{11}\right.$ viral particles $)$ were further assessed for safety [28]. Both doses produced significant neutralizing antibody response to live virus in Phase II trial involving 508 participants ( $\geq 18$ years old). GMTs of 19.5 (95\% CI 16.8-22.7) and 18.3 (14.4-23.3) were observed in those received $1 \times 10^{11}$ and $5 \times 10^{10}$ viral particles, respectively. Specific IFN- $\gamma$ responses post-vaccination were observed in 227 (90\%, 95\% CI 85-93) of 253 and 113 (88\%, 81-92) of 129 participants receiving the $1 \times 10^{11}$ and $5 \times 10^{10}$ viral particles, respectively. The Ad5-nCoV vaccine administered with a single dose consisting of $5 \times 10^{10}$ viral particles was found to be safe and could induce significant neutralizing antibody responses to SARS-CoV-2 in most of the participants. Since no serious adverse reactions were being reported after the single-dose immunization, the Ad5-nCoV vaccine progressed further to Phase III clinical trial with a single dose administration (NCT04526990) [37]. However, Th2 responses have not been reported in these studies thus far. The assessment of Th1/Th2 polarization including the levels of IL-4, IL-5 and IL-13 should be included in further studies to reduce the risk of vaccine-associated enhanced disease (VAERD).

\subsection{Chimpanzee adenovirus-vectored vaccine ChAdOx1 nCoV-19 (AZD1222)}

A chimpanzee adenovirus vectored vaccine ChAdOx1 nCoV-19 (AZD1222) encoding the spike protein of SARS-CoV-2 was developed by inserting a codonoptimized $S$ protein gene in a replication-defective vector ChAdOx1 [53] The vaccine was the culminating efforts between academia (Oxford University) and industrial collaboration (AstraZeneca). 
A Phase I/II trial enrolled 1077 healthy volunteers (aged 18-55 years) and participants were immunized with either a single dose or with two doses consisting of $5 \times 10^{5}$ viral particles that were administered 4 weeks apart. By day 28 after a single dose vaccination, antibodies capable of neutralizing live SARS-CoV-2 were reported and subsequent boosting was able to enhance antibody responses. Spike-specific $\mathrm{T}$ cell responses peaked on day 14 but declined by day 56 after vaccination [38]. ChAdOx1 nCoV19 (AZD1222) vaccination has been shown to induce both CD4+ and CD8+ T cell responses. CD4+ T cell responses were biased towards secretion of Th1 cytokines (IFN- $\gamma$ and IL-2) with minimal Th2 cytokines [41]. Participants who received the ChAdOx1 nCoV-19 (AZD1222) vaccine reported mild to moderate side effects such as pain, fatigue, fever, chills, malaise, headache. No serious side effects occurred 28 days after vaccination [38]. The production of robust humoral and cellular responses and acceptable safety supported the large-scale evaluation of ChAdOx1 nCoV19 (AZD1222) vaccine in a Phase III trial. This vaccine needs to be stored at $2-8^{\circ} \mathrm{C}$ which is more amenable to distribution in developing countries. A Phase III study involving 23,848 participants aged 18 years and older were randomly assigned to receive either the ChAdOx1 nCoV-19 (AZD1222) vaccine or a control (meningococcal vaccine or saline) (NCT04516746). Interim results of 11,636 volunteers in the United Kingdom and Brazil showed that vaccine efficacy in participants receiving two standard doses of $5 \times 10^{10}$ VP was $62.1 \%$. A higher vaccine efficacy (90\%) was reported for participants who received a low dose at $2.5 \times 10^{10}$ VP followed by a standard dose of $5 \times$ $10^{10}$ VP. Hence, the overall efficacy of ChAdOx1 nCoV19 (AZD1222) was reported at 70.4\% [54]. The study also showed that the transmission of SARS-CoV-2 by vaccinees was reduced by $67 \%$ after a single vaccination and $50 \%$ after two vaccinations [39]. Majority of the participants (79\%) from the Phase III UK study were younger (18-55 years of age), with only $12 \%$ of 2377 from the 56-69 age group and a small number of participants (9.0\%) from over 70 years of age. Immune responses were similar in the elderly after vaccination with two standard doses of ChAdOx1 nCoV-19 (AZD1222) [55]. The efficacy of the vaccine will need to be further evaluated in populations with pre-existing anti-ChAdOx1-neutralizing antibodies (>200) as anti-vector antibodies could affect the ultimate vaccine efficacy.

\subsection{Adenovirus-vectored vaccines (Sputnik V)}

Two vectors, adenovirus type 26 (Ad26) and adenovirus type 5 (Ad5), were used to construct the GamCOVID vaccine (Sputnik V) carrying the genes for the SARS-CoV-2 full-length glycoprotein S. Both recombinant vaccines (rAd26-S and rAd5-S) were developed by Gamaleya Research Institute of Epidemiology and Microbiology (Moscow, Russia).
In Phase I study, the safety and immunogenicity of the Gam-COVID vaccine were evaluated in nine volunteers who received the vaccine intramuscularly on day 0 , with either one dose of rAd26-S or one dose of rAd5-S and they were monitored for 28 days. In Phase II study, 20 volunteers were primed with rAd26-S, followed with booster vaccinations with one dose of rAd5-S on day 21. Both frozen and lyophilized vaccine formulations were safe, well-tolerated and elicited RBD-specific IgG as well as neutralizing antibodies. Side effects were mild to moderate (injection site pain, fever, headache, myalgia) but no serious adverse events were reported [29]. On day 42, neutralizing antibody responses were detected in all 40 participants in the Phase II trial with GMT levels of 49.25 elicited by the frozen formulation compared to 45.95 with the lyophilized formulation. A seroconversion rate of $100 \%$ was achieved after the second dose. The antibody responses in vaccinated volunteers were significantly higher than antibody levels observed in convalescent SARS-CoV-2 patients. CD4+ and CD8+ T cell responses occurred in 100\% of participants within 28 days of vaccination and increased IFN- $\gamma$ secretions by peripheral blood mononuclear cells were detected. The frozen formulation was found to have a slightly higher number of T-helper cells when compared to the lyophilized formulation (2.5\% versus $1.3 \%$ ). A minimal increase in the CD8+ T cells was observed for both frozen and lyophilized Sputnik V vaccine [29]. However, the risk of vaccine-associated enhanced disease remained uninvestigated as Th2 analysis was not included in the study. The Sputnik V vaccine, developed by the Russian Health Ministry's Gamaleya Institute, was found to induce both humoral and CD4+/CD8+ T cell response in Phase I/II studies. The vaccine showed a good safety profile in a small group of 76 participants but no control or placebo group was included. It can be stored at $-18^{\circ} \mathrm{C}$, instead of temperatures far below freezing being required for vaccines such as Pfizer's BNT162b2 vaccine.

A Phase III trial of Sputnik V vaccine was conducted in Russia involving 21,977 participants aged 18 years or older. A majority of the participants $(16,501)$ were vaccinated with two doses of Sputnik V vaccine while the placebo group only comprised 4476 participants. Interim analysis of Phase III trial showed 91.6\% efficacy against COVID-19 and good tolerability was reported in a large cohort (NCT04530396) [40]. The Gam-COVID-Vac (Sputnik $\mathrm{V}$ ) vaccine became the first coronavirus vaccine approved for use in Russia after its registration on August 11, 2020, ahead of completion of Phase III trials.

\subsection{Ad26.COV2.S}

Ad26.COV2.S is a replication-deficient recombinant adenovirus type 26 vector expressing the stabilized full-length pre-fusion spike (S) protein of SARS-CoV-2 and was developed by Janssen Pharmaceutical company of the Johnson and Johnson (J\&J) group. 
Phase I/IIa randomized, double-blinded, placebocontrolled clinical study was conducted to assess the safety, reactogenicity and immunogenicity of the Ad26.COV2.S vaccine in adults $18-55$ years $(n=402)$ and those $>65$ years of age $(n=394)$. After vaccination with either a single low dose at $5 \times 10^{10} \mathrm{VP}$ or high dose $1 \times 10^{11} \mathrm{VP}$, neutralizingantibody titers (GMT 224 to 354) were detected in 90\% or more of all participants on day 29. By day 57, further increase in neutralizing antibody titers were reported in $100 \%$ of participants. Regardless of vaccination dose or age group, neutralizing antibodies remained consistent until day 71. Higher levels of Th1 cytokine-producing Sspecific CD4+ T cell were detected in the younger adults than in older participants on day 14 post-vaccination. All the participants receiving a single dose of Ad26.COV2. S had a measurable Th1 or Th2 response with Th1/Th2 ratio well above 1 , indicating a vaccine-induced Th1-skewed response with low risk of VAERD. CD8+ T-cell responses were robust at both vaccine dosages for the younger participants but were lower in the elderly [30].

Vaccine safety and reactogenicity were evaluated in both younger (aged 18-55) and elderly cohorts ( $\geq 65$ years of age). Injection-site pain was the most common local adverse event in both groups. Fatigue, headache, and myalgia were the most common reported systemic adverse events. The results indicated that a single dose of Ad26.COV2. S administered either at $5 \times 10^{10}$ VP or $1 \times$ $10^{11} \mathrm{VP}$ was safe, well-tolerated and highly immunogenic [30]. The vaccine was reported to be stable for up to two years at $-20{ }^{\circ} \mathrm{C}$ with a shelf life of 3 months at 2 to $8{ }^{\circ} \mathrm{C}$. Based on similar immunogenicity elicited by both dosages, irrespective of age groups, Ad26.COV2.S was progressed to Phase III to evaluate the efficacy of either a single-dose (NCT04505722) or two-dose (NCT04614984) vaccination schedule using $5 \times 10^{10}$ viral particles. A randomized, double-blind Phase III clinical trial involving 60,000 participants aged 18 years and above was initiated in several countries. Interim data from a Phase III trial showed a 66\% efficacy in preventing moderate to severe COVID-19 29 days after vaccination in the USA. Ad26.COV2.S was approved by US FDA on 27 February 2021.

\section{Recombinant S protein-based vaccine NVX-CoV2373}

Novavax NVX-CoV2373 vaccine is a recombinant SARS-CoV-2 subunit vaccine containing the fulllength spike (S) glycoprotein stabilized in the prefusion conformation and Matrix-M1 adjuvant.

A phase 1/2 randomized, placebo-controlled trial for NVX-CoV2373 was conducted with 131 healthy adults (18-59 years of age) to evaluate the safety and immunogenicity of the rSARS-CoV-2 nanoparticle vaccine. Participants $(\mathrm{n}=83)$ were administered with 2 doses at $5 \mu \mathrm{g}$ or $25 \mu \mathrm{g}$ of NVX-CoV2373 with and without Matrix M1 ad- juvant and 23 participants received placebo on days 0 and 21.

The two dose regiments of $5 \mu \mathrm{g}$ and $25 \mu \mathrm{g}$ of NVX-CoV2373 adjuvanted with Matrix-M1 resulted in enhanced immune responses by eliciting high levels of antispike (S) IgG and neutralizing antibodies. Individuals receiving two doses of $5 \mu \mathrm{g}$ adjuvanted vaccine developed 10-fold higher anti-S neutralizing antibodies than those without adjuvant at Day 21. The neutralizing antibodies showed strong neutralizing activity (GMT: 3906) against live SARS-CoV-2 virus particles after the second vaccination. By day 21, all groups receiving adjuvanted vaccines had $100 \%$ seroconversion rates with detectable anti-Spike neutralizing antibodies. Antigen sparing was observed with the Matrix-M1 adjuvant as anti-Spike IgG levels elicited by the 2 doses of $5 \mu \mathrm{g}$ /dose were shown to be higher (63,160 GMEUs) than the levels elicited by the $25 \mu \mathrm{g}$ dose alone (at 47,521 GMEUs) at day 35.

Overall, individuals inoculated with the first dose of NVX-CoV2373 with Matrix-M1 adjuvant achieved neutralizing antibody levels similar to SARS-CoV-2 symptomatic patients. A second dose boosted the immunity conferred, causing the GMEU levels to rise to similar levels as convalescent sera from patients hospitalized with SARSCOV-2. Additionally, the dose sparing effect of Matrix-M1 was demonstrated based on similar neutralizing antibody levels in both groups receiving the $5 \mu$ g adjuvanted dose and the $25 \mu \mathrm{g}$ adjuvanted dose. Aside from neutralizing antibody response, the adjuvanted NVX-CoV2373 vaccine with Matrix-M1 triggered CD4+ T-cell activation which was Th1 biased, leading to secretions of IFN- $\gamma$, TNF- $\alpha$ and IL-2. Minimal Th2 responses were observed.

After the first vaccination, reactogenicity in the majority of the participants was mild or absent. The most common severe symptoms reported were headache, fatigue and malaise [31]. Press release from the UK Phase III trial on 28th January 2021 reported an efficacy of 89.3\% in over 20,000 participants (18-84 years of age with $27 \%$ over the age of 65\%) (NCT04611802). As it is stable at $2{ }^{\circ} \mathrm{C}$ to 8 ${ }^{\circ} \mathrm{C}$, it can be distributed easily. However, the South Africa Phase IIb trial showed a lower efficacy at $60 \%$ for the prevention of COVID-19 in HIV-negative participants. Prior infection with SARS-CoV-2 might not completely protect against the South Africa variant but the risks were reduced by $60 \%$ in NVX-CoV2373 vaccinated participants [56]. New constructs against the emerging South African strain have begun and could be developed as a booster or a bivalent vaccine candidate in future.

\section{The promise of COVID-19 vaccines and the emergence of variants}

The emergence and rapid spread of the SARSCoV-2 virus have fast-tracked the process of vaccine development. As of May 2021, vaccines such as BNT162b2 
mRNA vaccine, mRNA-1273 vaccine, adenovirus vectored vaccine ChAdOx1 nCov-19 (AZD1222) and an inactivated vaccine CoronaVac from Sinovac have been granted emergency use authorization from WHO and respective government authorities worldwide. FDA has approved the use of BNT162b2, mRNA-1273 and Ad26.COV2.S but not ChAdOx1 nCoV-19 (AZD1222), although the latter has been authorized for use by European Medicines Agency (EMA).

Immune responses vary with different vaccine platforms. mRNA, inactivated and subunit protein-based vaccines were reported to require two doses to achieve protection efficacy while adenovirus vectored vaccines such as the Ad5-nCoV and Ad26.COV2.S vaccines have been shown to evoke sufficient immune responses after a single dose of vaccination.

The spike (S) protein of SARS-CoV has been shown to play a crucial role in viral attachment and entry into host cells. The RBD in the SARS-CoV-2 spike protein was evaluated to be immunodominant and accounted for $90 \%$ of neutralizing activities [57]. Functional neutralizing antibodies specific for SARS-CoV-2 are important for viral neutralization and clearance. The lack of standardized GMT values to compare different efficacy studies and the use of different immunoassays by different vaccine developers as well as differences in dosages and schedules of administration, make it difficult to compare the efficacy of SARS-CoV-2 vaccine candidates that were in Phase III clinical trials. NVX-CoV2373 S protein vaccine was reported to elicit the highest neutralizing antibody titers, followed by the Ad26.COV2.S vaccine and the mRNA-1273 vaccine. The ChAdOx1 nCoV-19 (AZD1222) vaccine, BNT162b2 mRNA vaccine, BBIBP-CorV and New Crown inactivated vaccines produced neutralizing antibodies in the medium range. Lower neutralizing antibody GMTs were reported for the Sputnik V, CoronaVac and Ad5-nCoV.S vaccines. The less immunogenic vaccines might still elicit sufficient immunity to confer protection, but the protective role of antibody-mediated humoral responses against SARS-CoV2 is still unknown as the correlates of protection have not been established [58]. Ibarrondo et al. [59] (2020) reported that there was a rapid decay of anti-SARS-CoV-2 antibodies within 2-4 months post-infection in mild COVID-19 patients. The mRNA-based Moderna vaccine was shown to elicit antibodies that lasted for at least 6 months [60]. Thus, vaccination might promote persistence of humoral response for a longer period compared to natural infection. However, the persistence of SARS-CoV-2 neutralizing antibodies after vaccination with other vaccine candidates is still unknown. The levels of humoral response required to confer protection are unknown as the concentrations of neutralizing antibodies have not been shown to correlate with COVID-19 severity. Strong neutralizing antibody responses have been reported in patients with severe COVID19 infection and low antibody responses were observed in asymptomatic or patients with mild infection [61]. Thus, current knowledge suggested that in addition to humoral responses, cellular immune responses could play an important role in preventing SARS-CoV-2 infection. Studies of neutralizing antibody titers, memory B and T cells to SARSCoV-2 will be important for understanding the durability and types of protective immunity against SARS-CoV-2 infection.

The spike protein is the antigen used in most of the current SARS-CoV2 vaccines. However, spike protein is subjected to a relatively high rate of mutations. The vaccines focusing on the spike protein might not be effective or have reduced protection against SARS-CoV-2 variants such as B.1.1.7 and B.1.351 that carried spike (S)-protein mutations [62]. CD4+ T cell responses have been reported to be mostly directed against the $\mathrm{S}, \mathrm{M}$, and $\mathrm{N}$ proteins and partially against nsp3, nsp4, and ORF8 whilst CD8+ T cell responses were directed against immunogenic peptides not only from the $\mathrm{S}$ protein but also from $\mathrm{M}$, and partially from the nsp3, nsp6 and ORF3a [63]. Peng et al. [64] (2020) identified six immunodominant T cell epitopes (3 from $\mathrm{S}$ protein, 2 from $\mathrm{M}$ protein and 1 from $\mathrm{N}$ protein) which were recognized by sera from UK COVID-19 convalescent patients. Thus, the conserved regions from $\mathrm{M}$ and $\mathrm{N}$ proteins can be included as target antigens in future vaccines to stimulate the response of effector $\mathrm{T}$ cells against emerging SARS-CoV-2 variants. With the exception of inactivated vaccines, all vaccines currently in Phase III have shown the ability to elicit potent Th1 responses. It is characterized by the secretions of IFN- $\gamma$, IL-2 and TNF$\alpha$, with low Th2 response characterized by the cytokine IL4 , which minimizes the risk or potential VAERD. The risk factors for severe COVID-19 were related to an increased number of Th17 cells where accumulation of Th17 cells in the lungs could lead to excessive inflammation seen in severe COVID-19 infections. Therefore, further resolutions of Th1, Th2 and Th17 responses elicited by the respective vaccines are needed.

Nainu et al. [65] (2020) reported that reinfection with SARS-CoV-2 is possible in humans and most of the reinfection cases were reported from China. Recent vaccine breakthrough infections with SARS-CoV-2 variants were also reported in two patients who were fully vaccinated with BNT162b2 or mRNA-1273 at least 2 weeks prior to re-infection in the USA [66]. The total CD4+ and CD8+ T-cells were found to be substantially reduced in COVID-19 patients, particularly those who needed intensive care. The percentages of PD-1+CD8+, CD4+ T-cells and Tim-3+CD4+ T-cells in ICU patients with COVID19 disease were significantly higher, implying that SARSCoV-2 could lead to dysfunctional of T cells in COVID19 patients [67]. Moreover, decreased quantity or quality of $\mathrm{B}$ cells or memory $\mathrm{T}$ cells might also dampen the immune responses in patients with reinfections. Patients with lymphopenia could lead to suboptimal production of neutralizing antibodies and reduced functional activities 
of effector $\mathrm{T}$ cells, leading to increased susceptibility to SARS-CoV-2 reinfection. In addition, elevated levels of pro-inflammatory cytokines might contribute to lymphocyte killing in COVID-19 patients [68]. Increased proinflammatory cytokine levels such as IL-6, IL-10, and TNF$\alpha$ and decreased IFN- $\gamma$ expressing CD4+ T-cells were reported in patients with severe COVID-19 [69]. Reinfection is possible in immunodeficient individuals with low antibody titers or those who failed to generate sufficient memory cells [70]. Emerging new SARS-CoV-2 variants might also increase the chances of reinfection as the antibodies produced in the primary infection might have decreased ability to recognize the epitopes of the new variants [71]. The choice of vaccines might also a factor contributing to reinfection. An effective vaccine should mount sufficient numbers of memory $\mathrm{T}$ and $\mathrm{B}$ cells as well as long-lasting neutralizing antibodies against the virus. Inactivated vaccines often fail to induce cellular responses and required the addition of an adjuvant to boost the responses or multiple vaccinations. Therefore, vaccine design using conserved antibody recognition site (B cell) and T cell epitopes may help to prevent severe re-infections of SARS-CoV-2.

In contrast to inactivated vaccines, only the cellular immune responses for BNT162b2, mRNA-1273, Ad5-nCoV, ChAdOx1 nCoV-19 (AZD1222), Sputnik V, Ad26.COV2.S and NVX-CoV2373 have been characterized. $\mathrm{T}$ cell immunity might contribute to longer-term immunogenicity against SARS-CoV-2 instead of the neutralizing antibodies which were determined for the current COVID-19 vaccines. Together with the emergence of SARS-CoV-2 variants, this might necessitate the search for highly conserved B and T cell epitopes to be incorporated into a "universal vaccine" which can confer broad protection over a longer-term. The "universal vaccine" could be used as a pre-pandemic vaccine to prevent re-infection by variants or infection from other coronavirus strains capable of causing pandemics in the future.

The inactivated vaccine CoronaVac, New Crown COVID-19 and NVX-CoV2373 are the only vaccines that have not been assessed for their efficacy and safety in the elderly $\geq 65$ years of age. Besides age groups, several COVID-19 vaccines are currently being evaluated in different ethnic populations involving children and adolescents below 18 years of age, pregnant women, lactating mothers and individuals with co-morbidities.

As currently approved COVID-19 vaccines contain no live viruses, the risk of COVID-19 vaccine is low in pregnant and lactating women. CDC has indicated no significant differences in safety profiles postvaccination in pregnant versus non-pregnant women from 16 to 54 years old who receive mRNA vaccines [72]. Both Moderna mRNA-1273 and Pfizer BNT162b2 vaccines generated similar immunogenicity and reactogenicity profiles in pregnant and lactating women which were comparable to non-pregnant women. The antibodies produced by the mRNA vaccine were present in infant cord blood and breastmilk samples, suggesting that vaccination could confer robust maternal and neonatal humoral immunity [73]. Cross-reactive antibody and $\mathrm{T}$ cell responses were evaluated against SARS-CoV-2 B.1.1.7 and B.1.351 variants post-vaccination. The neutralizing antibody titers in nonpregnant, pregnant, and lactating women were reduced against the B.1.1.7 variant (3.5-fold) and B.1.351 variant (6fold) when compared to the SARS-CoV-2-USA-WA1/2020 Wuhan strain [74].

Pfizer BNT162b2 vaccine was shown to have lower vaccine effectiveness for those with chronic comorbidities including high blood pressure, COPD, immunosuppression and type-2 diabetes [75, 76]. It is known that comorbidities are risk factors for severe COVID-19 outcomes. As a preventive measure, COVID-19 vaccination is most needed for those more vulnerable individuals which could reduce the mortality rate of those with underlying diseases. Antibody responses were markedly diminished after the first immunization in cancer patients but often improve after the second vaccination of BNT162b2 [77]. A recent study found that $90 \%$ of cancer patients exhibited sufficient antibody response to two doses of the BNT162b2 vaccination, despite having significantly lower antibody titers than healthy controls [78]. These observations supported vaccinations would reduce the likelihood of severe COVID-19 in cancer patients. The reactogenicity, antibody enhancement effects (ADE), VAERD, protection conferred by neutralizing antibodies and $T$ cells will need to be monitored over a longer-term period of more than 2 years after vaccination in Phase IV trials. ChAdOx1 nCoV-19 (AZD1222) vaccine was associated with blood clots including rare cases of cerebral venous sinus thrombosis (CVST) and disseminated intravascular coagulation (DIC). European Medicines Agency (EMA) concluded that ChAdOx1 nCoV-19 (AZD1222) vaccine is safe as the overall risk of these blood clots is extremely rare with 25 cases in 20 million who received the vaccine in the United Kingdom [79]. Despite adverse effects, the risk of COVID-19 infections were higher than the danger posed by blood clots, hence it is still acceptable as an effective vaccine in many countries.

In view of the emergence of new SARS-CoV2 variants, the immunogenicity and efficacy of the current vaccines that have been approved for emergency use will need to be further evaluated against these newly evolved variants. Convalescent plasma showed no significant changes in neutralizing activities against B.1.1.7 but the reduction against B.1.351 was significant [62]. Sera from vaccinated individuals with BNT162b2 had approximately two-third lower neutralizing activities against the B.1.351 variant compared to the Wuhan SARS-CoV-2 isolate [80]. Neutralizing activity elicited by mRNA-1273 vaccine against the spike protein of B.1.351 variants was reported to be 6-fold lower than the original Wuhan-Hu-1 strain [81]. However, the antibodies might still provide suf- 
ficient protection against COVID-19. Decreased efficacy of NVX-CoV2373, Ad26.COV2.S and ChAdOx1 nCoV19 (AZD1222) vaccines against B.1.351 had also been reported. Novavax NVX-CoV2373 vaccine efficacy was 89.3\% against the UK variant but was only $60 \%$ effective against the South African variant [56]. Ad26.COV2.S vaccine was 66\% effective in Latin America and only achieved $57 \%$ efficacy in South Africa [82]. The efficacy of ChAdOx1 nCoV-19 (AZD1222) was 70\% in the UK and Brazil but was reported to be only $22 \%$ against mild to moderate COVID-19 infections in South Africa [83]. Pfizer BNT162b2 and ChAdOx1 nCoV-19 (AZD1222) vaccine was found to be highly effective against Indian variant B.1.617.2 at $88 \%$ and $60 \%$, respectively [84]. Neutralizing activity in the ChAdOx1 nCoV-19 (AZD1222) vaccineelicited serum was 9-fold lower against the B.1.351 variant than the UK strain [85]. Since the current vaccines have been reported to have lower efficacies against the South Africa variants (B.1.351 lineage) [62], there may be a need to construct new vaccines which include novel mRNA or proteins (recombinant protein subunit) of new variants as boosters in subsequent vaccinations.

Real-world evidence is provided by the usage and post-market safety or adverse events being reported for current vaccines. This data can be generated from a large cohort of participants in Phase IV clinical trials and is expected to strengthen the evidence gathered relating to the efficacy of a vaccine. The study of approximately $99 \%$ of Scotland's population (5.4 million people) provided reassurance that the Oxford-AstraZeneca ChAdOx1 nCoV19 (AZD1222) and Pfizer BNT162b2 vaccines could significantly reduce COVID-19 hospitalizations and fatalities among the elderly after the first dose [86]. Real-world evidence reported that the incidence of COVID-19 was dramatically lowered in individuals who were fully vaccinated with the Pfizer BNT162b2 vaccine. The likelihood of contracting and developing COVID-19 was 44 times more for individuals who were not vaccinated while the chances of mortality were likely to be 29 times more than vaccinated individuals. This confirmed the higher level of effective protection with BNT162b2 vaccine. BNT162b2 and ChAdOx1 nCoV-19 (AZD1222) vaccines had demonstrated $91 \%$ and $88 \%$ reduction, respectively in hospitalizations after the first dose based on 1.33 million COVID19 vaccinations administered in Scotland, UK. The use of ChAdOx1 nCoV-19 (AZD1222) was supported in older individuals as the majority of those receiving this vaccine were over 80 years old and the effects of the vaccine were observed to be comparable across all age groups [87].

\section{Conclusions}

Some of the current vaccines have demonstrated $>90 \%$ efficacy but protective efficacy of vaccines was reported to decline due to emergence of new variants such as the South Africa B.1.351 and Indian B.1.617.2 variants. However, the vaccines still retain some effectiveness in preventing the spread of new variants even though the neutralizing antibody titers had declined. Correlates of protection for each vaccine will need to be established by creating a central database to assess multiple variables. The immunogenicity of existing vaccines can be improved by adding a booster dose or by using alternate vaccines to ensure sufficient protection against SARS-CoV-2 variants. The need to construct multivalent vaccines that may be effective in preventing the spread of SARS-CoV-2 variants that have high transmissibility or pathogenicity. A booster vaccine mRNA-1273.351 was developed by Moderna to cater for emerging variants B.1.351[88] while next generation multivalent mRNA vaccine is in development phase by joint efforts of GlaxoSmithKline plc and CureVac N.V. [89]. Standardized methods of data generation for neutralizing antibodies and $\mathrm{T}$ cell responses are needed to ensure the protective efficacy of new vaccine candidates in clinical research.

In addition to safety and efficacy, other factors including cost of production, ease of distribution, storage stability and long-term immunity should be monitored. All the vaccines currently in Phase III evaluations were administered intramuscularly. However, several intranasal vaccine formulations which can be easily administered are currently being investigated [90, 91] and would be beneficial as mucosal immunity is known to offer the first line of defense against the virus. The secretion of mucosal IgA in the upper respiratory tract during initial contact with the SARSCoV-2 virus could contribute to early protection against COVID-19 infection. Several of the vaccine candidates are facing distribution problems, especially in underdeveloped and developing countries as they have to be stored at ultracold temperatures. The BNT162b2 mRNA vaccine requires storage at $-70{ }^{\circ} \mathrm{C}$ for longer-term storage but it can be stored at $-20^{\circ} \mathrm{C}$ for up to 2 weeks. It faces a massive logistics challenge for distribution in underdeveloped nations. Efforts to develop thermostable formulation such as lyophilized vaccines for longer-term storage will overcome the logistics of distributions in developing countries.

\section{Author contributions}

HXL, AAAY, and SDJ wrote the manuscript. HXL prepared the tables. MA reviewed the manuscript and acquired funding for the article processing charge. SP reviewed and edited the manuscript. CLP supervised, edited and reviewed the manuscript.

\section{Ethics approval and consent to participate}

Not applicable. 


\section{Acknowledgment}

We would like to thank the Director General of Health Malaysia for his permission to publish this article.

\section{Funding}

This study was funded by Individual Research Grants 2021 (GRTIN-IRG-15-2021 and GRTIN-IRG-512021) to Chit Laa Poh and Hui Xuan Lim from the Centre for Virus and Vaccine Research (CVVR), School of Medical and Life Sciences, Sunway University.

\section{Conflict of interest}

The authors declare no conflict of interest.

\section{References}

[1] Krammer F. SARS-CoV-2 vaccines in development. Nature. 2020; 586: 516-527.

[2] de Lusignan S, Dorward J, Correa A, Jones N, Akinyemi O, Amirthalingam $\mathrm{G}$, et al. Risk factors for SARS-CoV-2 among patients in the Oxford Royal College of General Practitioners Research and Surveillance Centre primary care network: a cross-sectional study. The Lancet Infectious Diseases. 2020; 20: 1034-1042.

[3] Baden LR, El Sahly HM, Essink B, Kotloff K, Frey S, Novak $\mathrm{R}$, et al. Efficacy and Safety of the mRNA-1273 SARS-CoV-2 Vaccine. New England Journal of Medicine. 2021; 384: 403416.

[4] Yip MS, Leung HL, Li PH, Cheung CY, Dutry I, Li D, et al. Antibody-dependent enhancement of SARS coronavirus infection and its role in the pathogenesis of SARS. Hong Kong Medical Journal. 2016; 22: 25-31.

[5] Wan Y, Shang J, Sun S, Tai W, Chen J, Geng Q, et al. Molecular Mechanism for Antibody-Dependent Enhancement of Coronavirus Entry. Journal of Virology. 2020; 94: e02015-19.

[6] Hotez PJ, Corry DB, Bottazzi ME. COVID-19 vaccine design: the Janus face of immune enhancement. Nature Reviews Immunology. 2020; 20: 347-348.

[7] Quinlan BD, Mou H, Zhang L, Guo Y, He W, Ojha A, et al. The SARS-CoV-2 receptor-binding domain elicits a potent neutralizing response without antibody-dependent enhancement. Available at: https://ssrn.com/abstract=3575134 or http://dx.doi.org /10.2139/ssrn.3575134 (Accessed: 30 September 2021).

[8] Hotez PJ, Bottazzi ME. Developing a low-cost and accessible COVID-19 vaccine for global health. PLoS neglected tropical diseases. 2020; 14: e0008548.

[9] Graham BS. Rapid COVID-19 vaccine development. Science. 2020; 368: 945-946.

[10] Connors M, Giese NA, Kulkarni AB, Firestone CY, Morse HC, Murphy BR. Enhanced pulmonary histopathology induced by respiratory syncytial virus (RSV) challenge of formalininactivated RSV-immunized BALB/c mice is abrogated by depletion of interleukin-4 (IL-4) and IL-10. Journal of Virology. 1994; 68: 5321-5325.

[11] Yasui F, Kai C, Kitabatake M, Inoue S, Yoneda M, Yokochi S, et al. Prior immunization with severe acute respiratory syndrome (SARS)-associated coronavirus (SARS-CoV) nucleocapsid protein causes severe pneumonia in mice infected with SARS-CoV. Journal of Immunology. 2008; 181: 6337-6348.

[12] Tseng C, Sbrana E, Iwata-Yoshikawa N, Newman PC, Garron
T, Atmar RL, et al. Immunization with SARS coronavirus vaccines leads to pulmonary immunopathology on challenge with the SARS virus. PloS one. 2012; 7: e35421.

[13] Agrawal AS, Tao X, Algaissi A, Garron T, Narayanan K, Peng $\mathrm{B}$, et al. Immunization with inactivated Middle East Respiratory Syndrome coronavirus vaccine leads to lung immunopathology on challenge with live virus. Human Vaccines \& Immunotherapeutics. 2016; 12: 2351-2356.

[14] Bolles M, Deming D, Long K, Agnihothram S, Whitmore A, Ferris $\mathrm{M}$, et al. A double-inactivated severe acute respiratory syndrome coronavirus vaccine provides incomplete protection in mice and induces increased eosinophilic proinflammatory pulmonary response upon challenge. Journal of Virology. 2011; 85: 12201-12215.

[15] Development and licensure of vaccines to prevent COVID19. 2020. Available at: https://Www.Fda.Gov/Media/139638/ Download (Accessed: 30 September 2021).

[16] Poland GA, Ovsyannikova IG, Kennedy RB. SARS-CoV-2 immunity: review and applications to phase 3 vaccine candidates The Lancet. 2020; 396: 1595-1606.

[17] Chowdhury MA, Hossain N, Kashem MA, Shahid MA, Alam A. Immune response in COVID-19: a review. Journal of Infection and Public Health. 2020; 13: 1619-1629.

[18] Smith KM, Pottage L, Thomas ER, Leishman AJ, Doig TN, Xu $\mathrm{D}$, et al. Th1 and Th2 CD4+ T cells provide help for B cell clonal expansion and antibody synthesis in a similar manner in vivo. Journal of Immunology. 2000; 165: 3136-3144.

[19] Zhu J, Yamane H, Paul WE. Differentiation of Effector CD4 T Cell Populations. Annual Review of Immunology. 2010; 28: 445-489.

[20] Kadkhoda K. COVID-19: an Immunopathological View. MSphere. 2020; 5: e00344-20.

[21] Wang F, Nie J, Wang H, Zhao Q, Xiong Y, Deng L, et al. Characteristics of Peripheral Lymphocyte Subset Alteration in COVID19 Pneumonia. the Journal of Infectious Diseases. 2020; 221: 1762-1769.

[22] Cecere TE, Todd SM, Leroith T. Regulatory T cells in arterivirus and coronavirus infections: do they protect against disease or enhance it? Viruses. 2012; 4: 833-846.

[23] Ng O, Chia A, Tan AT, Jadi RS, Leong HN, Bertoletti A, et al. Memory T cell responses targeting the SARS coronavirus persist up to 11 years post-infection. Vaccine. 2016; 34: 2008-2014.

[24] Gallais F, Velay A, Wendling M-J, Nazon C, Partisani M, Sibilia $\mathrm{J}$, et al. Intrafamilial exposure to SARS-CoV-2 induces cellular immune response without seroconversion. Emerging Infectious Diseases. 2021; 27: 113-121.

[25] Sekine T, Perez-Potti A, Rivera-Ballesteros O, Strålin K, Gorin $\mathrm{JB}$, Olsson A, et al. Robust T cell immunity in convalescent individuals with asymptomatic or mild COVID-19. Cell. 2020; 183: 158-168.

[26] Jackson LA, Anderson EJ, Rouphael NG, Roberts PC, Makhene $\mathrm{M}$, Coler RN, et al. An mRNA Vaccine against SARS-CoV-2Preliminary Report. New England Journal of Medicine. 2020; 383: 1920-1931.

[27] Walsh EE, Frenck RW, Falsey AR, Kitchin N, Absalon J, Gurtman A, et al. Safety and Immunogenicity of Two RNABased Covid-19 Vaccine Candidates. New England Journal of Medicine. 2020; 383: 2439-2450.

[28] Zhu F, Li Y, Guan X, Hou L, Wang W, Li J, et al. Safety, tolerability, and immunogenicity of a recombinant adenovirus type5 vectored COVID-19 vaccine: a dose-escalation, open-label, non-randomised, first-in-human trial. The Lancet. 2020; 395: 1845-1854.

[29] Logunov DY, Dolzhikova IV, Zubkova OV, Tukhvatullin AI, Shcheblyakov DV, Dzharullaeva AS, et al. Safety and immunogenicity of an rAd26 and rAd5 vector-based heterologous primeboost COVID-19 vaccine in two formulations: two open, nonrandomised phase 1/2 studies from Russia. The Lancet. 2020; 396: 887-897. 
[30] Sadoff J, Le Gars M, Shukarev G, Heerwegh D, Truyers C, de Groot AM, et al. Interim Results of a Phase 1-2a Trial of Ad26.COV2.S Covid-19 Vaccine. New England Journal of Medicine. 2021; 384: 1824-1835.

[31] Keech C, Albert G, Cho I, Robertson A, Reed P, Neal S, et al. Phase 1-2 Trial of a SARS-CoV-2 Recombinant Spike Protein Nanoparticle Vaccine. New England Journal of Medicine. 2020; 383: 2320-2332.

[32] Xia S, Zhang Y, Wang Y, Wang H, Yang Y, Gao GF, et al. Safety and immunogenicity of an inactivated SARS-CoV-2 vaccine, BBIBP-CorV: a randomised, double-blind, placebo-controlled, phase 1/2 trial. The Lancet Infectious Diseases. 2021; 21: 3951.

[33] Xia S, Duan K, Zhang Y, Zhao D, Zhang H, Xie Z, et al. Effect of an Inactivated Vaccine against SARS-CoV-2 on Safety and Immunogenicity Outcomes. JAMA. 2020; 324: 951.

[34] Zhang Y, Zeng G, Pan H, Li C, Hu Y, Chu K, et al. Safety, tolerability, and immunogenicity of an inactivated SARS-CoV-2 vaccine in healthy adults aged 18-59 years: a randomised, doubleblind, placebo-controlled, phase 1/2 clinical trial. The Lancet Infectious Diseases. 2021; 21: 181-192.

[35] Anderson EJ, Rouphael NG, Widge AT, Jackson LA, Roberts PC, Makhene M, et al. Safety and Immunogenicity of SARSCoV-2 mRNA-1273 Vaccine in Older Adults. New England Journal of Medicine. 2020; 383: 2427-2438.

[36] Polack FP, Thomas SJ, Kitchin N, Absalon J, Gurtman A, Lockhart S, et al. Safety and Efficacy of the BNT162b2 mRNA Covid-19 Vaccine. New England Journal of Medicine. 2020; 383: 2603-2615.

[37] Zhu F, Guan X, Li Y, Huang J, Jiang T, Hou L, et al. Immunogenicity and safety of a recombinant adenovirus type-5-vectored COVID-19 vaccine in healthy adults aged 18 years or older: a randomised, double-blind, placebo-controlled, phase 2 trial. The Lancet. 2020; 396: 479-488.

[38] Folegatti PM, Ewer KJ, Aley PK, Angus B, Becker S, BelijRammerstorfer S, et al. Safety and immunogenicity of the ChAdOx1 nCoV-19 vaccine against SARS-CoV-2: a preliminary report of a phase $1 / 2$, single-blind, randomised controlled trial. The Lancet. 2020; 396: 467-478.

[39] Voysey M, Clemens SAC, Madhi SA, Weckx LY, Folegatti PM, Aley PK, et al. Safety and efficacy of the ChAdOx1 nCoV-19 vaccine (AZD1222) against SARS-CoV-2: an interim analysis of four randomised controlled trials in Brazil, South Africa, and the UK. The Lancet. 2021; 397: 99-111.

[40] Logunov DY, Dolzhikova IV, Shcheblyakov DV, Tukhvatulin AI, Zubkova OV, Dzharullaeva AS, et al. Safety and efficacy of an rAd26 and rAd5 vector-based heterologous prime-boost COVID-19 vaccine: an interim analysis of a randomised controlled phase 3 trial in Russia. The Lancet. 2021; 397: 671-681.

[41] Ewer KJ, Barrett JR, Belij-Rammerstorfer S, Sharpe H, Makinson R, Morter R, et al. T cell and antibody responses induced by a single dose of ChAdOx1 nCoV-19 (AZD1222) vaccine in a phase 1/2 clinical trial. Nature medicine. 2021; 27: 270-278.

[42] Wang H, Zhang Y, Huang B, Deng W, Quan Y, Wang W, et al. Development of an Inactivated Vaccine Candidate, BBIBPCorV, with Potent Protection against SARS-CoV-2. Cell. 2020; 182: 713-721.

[43] van Riel D, de Wit E. Next-generation vaccine platforms for COVID-19. Nature Materials. 2020; 19: 810-812.

[44] Sinopharm. Chinese Covid vaccine gets WHO emergency approval. 2021. Available at: https://www.bbc.com/news/world-a sia-china-56967973 (Accessed: 30 September 2021).

[45] Gao Q, Bao L, Mao H, Wang L, Xu K, Yang M, et al. Development of an inactivated vaccine candidate for SARS-CoV-2. Science. 2020; 369: 77-81.

[46] China COVID vaccine reports mixed results-what does that mean for the pandemic? 2021. Available at: https://doi.org/10. 1038/d41586-021-00094-z (Accessed: 30 September 2021).

[47] Wang F, Kream RM, Stefano GB. An evidence based perspective on mRNA-SARS-CoV-2 vaccine development. Medical Science Monitor. 2020; 26: e924700.

[48] Wrapp D, Wang N, Corbett KS, Goldsmith JA, Hsieh C, Abiona $\mathrm{O}$, et al. Cryo-EM structure of the 2019-nCoV spike in the prefusion conformation. Science. 2020; 367: 1260-1263.

[49] Knezevic I, Liu MA, Peden K, Zhou T, Kang HN. Development of mRNA vaccines: scientific and regulatory issues. Vaccines. 2021; 9: 81.

[50] Mulligan MJ, Lyke KE, Kitchin N, Absalon J, Gurtman A, Lockhart S, et al. Phase iII study of COVID-19 RNA vaccine BNT162b1 in adults. Nature. 2020; 586: 589-593.

[51] Sahin U, Muik A, Vogler I, Derhovanessian E, Kranz LM, Vormehr M, et al. BNT162b2 vaccine induces neutralizing antibodies and poly-specific T cells in humans. Nature. 2021; 595: 572-577.

[52] FDA allows storage, transport of Pfizer vaccine at higher temperatures. 2021. Available at: https: //www.reuters.com/article/us-health-coronavirus-pfizer-v accine/fda-allows-storage-transport-of-pfizer-vaccine-a t-higher-temperatures-idUSKBN2AP2YK (Accessed: 30 September 2021).

[53] van Doremalen N, Lambe T, Spencer A, Belij-Rammerstorfer S, Purushotham JN, Port JR, et al. ChAdOx1 nCoV-19 vaccine prevents SARS-CoV-2 pneumonia in rhesus macaques. Nature. 2020; 586: 578-582.

[54] Voysey M, Costa Clemens SA, Madhi SA, Weckx LY, Folegatti PM, Aley PK, et al. Single-dose administration and the influence of the timing of the booster dose on immunogenicity and efficacy of ChAdOx1 nCoV-19 (AZD1222) vaccine: a pooled analysis of four randomised trials. The Lancet. 2021; 397: 881-891.

[55] Ramasamy MN, Minassian AM, Ewer KJ, Flaxman AL, Folegatti PM, Owens DR, et al. Safety and immunogenicity of ChA$\mathrm{dOx} 1 \mathrm{nCoV}-19$ vaccine administered in a prime-boost regimen in young and old adults (COV002): a single-blind, randomised, controlled, phase 2/3 trial. The Lancet. 2020; 396: 1979-1993.

[56] Novavax COVID-19 vaccine demonstrates $89.3 \%$ efficacy in UK phase 3 trial [press release]. Press release Novavax. 2021.

[57] Piccoli L, Park Y-J, Tortorici MA, Czudnochowski N, Walls AC, Beltramello M, et al. Mapping neutralizing and immunodominant sites on the SARS-CoV-2 spike receptor-binding domain by structure-guided high-resolution serology. Cell. 2020; 183: 1024-1042.

[58] Karim SSA. Vaccines and SARS-CoV-2 variants: the urgent need for a correlate of protection. The Lancet. 2021; 397: 12631264.

[59] Ibarrondo FJ, Fulcher JA, Goodman-Meza D, Elliott J, Hofmann C, Hausner MA, et al. Rapid Decay of Anti-SARS-CoV-2 Antibodies in Persons with Mild Covid-19. New England Journal of Medicine. 2020; 383: 1085-1087.

[60] Doria-Rose N, Suthar MS, Makowski M, O’Connell S, McDermott AB, Flach B, et al. Antibody Persistence through 6 Months after the second Dose of mRNA-1273 Vaccine for Covid-19. New England Journal of Medicine. 2021; 384: 2259-2261.

[61] Tan W, Lu Y, Zhang J, Wang J, Dan Y, Tan Z, et al. Viral kinetics and antibody responses in patients with COVID-19. medRxiv. 2020; DOI: 10.1101/2020.03.24.20042382.

[62] Wang P, Nair MS, Liu L, Iketani S, Luo Y, Guo Y, et al. Antibody resistance of SARS-CoV-2 variants B.1.351 and B.1.1.7. Nature. 2021; 593: 130-135.

[63] Grifoni A, Weiskopf D, Ramirez SI, Mateus J, Dan JM, Moderbacher CR, et al. Targets of T Cell Responses to SARS-CoV2 Coronavirus in Humans with COVID-19 Disease and Unexposed Individuals. Cell. 2020; 181: 1489-1501.

[64] Peng Y, Mentzer AJ, Liu G, Yao X, Yin Z, Dong D, et al. Broad and strong memory CD4+ and CD8+ T cells induced by SARSCoV-2 in UK convalescent individuals following COVID-19. Nature Immunology. 2020; 21: 1336-1345.

[65] Nainu F, Abidin RS, Bahar MA, Frediansyah A, Emran TB, Rabaan AA, et al. SARS-CoV-2 reinfection and implications for 
vaccine development. Human Vaccines \& Immunotherapeutics. 2020; 16: 3061-3073.

[66] Hacisuleyman E, Hale C, Saito Y, Blachere NE, Bergh M, Conlon EG, et al. Vaccine Breakthrough Infections with SARS-CoV2 Variants. New England Journal of Medicine. 2021; 384: 2212 2218.

[67] Diao B, Wang C, Tan Y, Chen X, Liu Y, Ning L, et al. Reduction and functional exhaustion of $\mathrm{T}$ cells in patients with coronavirus disease 2019 (COVID-19). Frontiers in immunology. 2020; 11: 827.

[68] Tang Y, Liu J, Zhang D, Xu Z, Ji J, Wen C. Cytokine storm in COVID-19: the current evidence and treatment strategies. Frontiers in immunology. 2020; 11: 1708.

[69] Pedersen SF, Ho Y. SARS-CoV-2: a storm is raging. Journal of Clinical Investigation. 2020; 130: 2202-2205.

[70] Mulder M, van der Vegt D, Oude Munnink BB, GeurtsvanKessel $\mathrm{CH}$, van de Bovenkamp J, Sikkema RS, et al. Reinfection of SARS-CoV-2 in an immunocompromised patient: a case report [manuscript published online ahead of print 9 October 2020]. Clinical Infectious Diseases. 2020.

[71] Bian L, Gao F, Zhang J, He Q, Mao Q, Xu M, et al. Effects of SARS-CoV-2 variants on vaccine efficacy and response strategies. Expert review of vaccines. 2021; 20: 365-373.

[72] Centers for Disease Control and Prevention. Vaccine safety. Vsafe after vaccination health checker. 2021. Available at: https: //www.cdc.gov/vaccinesafety (Accessed: 30 September 2021).

[73] Gray KJ, Bordt EA, Atyeo C, Deriso E, Akinwunmi B, Young N, et al. Coronavirus disease 2019 vaccine response in pregnant and lactating women: a cohort study. American Journal of Obstetrics and Gynecology. 2021; 225: 303.e1-303.e17.

[74] Collier AY, McMahan K, Yu J, Tostanoski LH, Aguayo R, Ansel $\mathrm{J}$, et al. Immunogenicity of COVID-19 mRNA Vaccines in Pregnant and Lactating Women. JAMA. 2021; 325: 2370.

[75] Dagan N, Barda N, Kepten E, Miron O, Perchik S, Katz MA, et al. BNT162b2 mRNA Covid-19 Vaccine in a Nationwide Mass Vaccination Setting. New England Journal of Medicine. 2021; 384: 1412-1423.

[76] Yelin I, Katz R, Herzel E, Berman-Zilberstein T, Ben-Tov A, Kuint J, et al. Associations of the BNT162b2 COVID-19 vaccine effectiveness with patient age and comorbidities. medRxiv. 2021; DOI:10.1101/2021.03.16.21253686

[77] Monin L, Laing AG, Muñoz -Ruiz M, McKenzie DR, del Molino del Barrio I, Alaguthurai T, et al. Safety and immunogenicity of one versus two doses of the COVID-19 vaccine BNT162b2 for patients with cancer: interim analysis of a prospective observational study. The Lancet Oncology. 2021; 22: 765-778.

[78] Massarweh A, Eliakim-Raz N, Stemmer A, Levy-Barda A, YustKatz S, Zer A, et al. Evaluation of Seropositivity Following BNT162b2 Messenger RNA Vaccination for SARS-CoV-2 in Patients Undergoing Treatment for Cancer. JAMA Oncology. 2021; 7: 1133.

[79] COVID-19 Vaccine AstraZeneca: benefits still outweigh the risks despite possible link to rare blood clots with low blood platelets. 2021. Available at: https://www.ema.europa.eu/en /news/covid-19-vaccine-astrazeneca-benefits-still-outweig h-risks-despite-possible-link-rare-blood-clots (Accessed: 30 September 2021).

[80] Liu Y, Liu J, Xia H, Zhang X, Fontes-Garfias CR, Swanson KA, et al. Neutralizing Activity of BNT162b2-Elicited Serum. New England Journal of Medicine. 2021; 384: 1466-1468.
[81] Wu K, Werner AP, Koch M, Choi A, Narayanan E, StewartJones GBE, et al. Serum Neutralizing Activity Elicited by mRNA-1273 Vaccine. New England Journal of Medicine. 2021; 384: $1468-1470$

[82] Johnson \& Johnson Announces Single-Shot Janssen COVID-19 Vaccine Candidate Met Primary Endpoints in Interim Analysis of its Phase 3 ENSEMBLE Trial. 2021. Available at: https://www.jnj.com/johnson-and-johnson-announces-sing e-shot-janssen-covid-19-vaccine-candidate-met-primary-e ndpoints-in-interim-analysis-of-its-phase-3-ensemble-trial (Accessed: 30 September 2021).

[83] Madhi SA, Baillie V, Cutland CL, Voysey M, Koen AL, Fairlie L, et al. Safety and efficacy of the ChAdOx1 nCoV-19 (AZD1222) Covid-19 vaccine against the B.1.351 variant in South Africa. New England Journal of Medicine. 2021; 384: 1885-1898.

[84] Bernal JL, Andrews N, Gower C, Gallagher E, Simmons R, Thelwall S, et al. Effectiveness of COVID-19 vaccines against the B.1.617.2 variant. New England Journal of Medicine. 2021; 385: 585-594.

[85] Zhou D, Dejnirattisai W, Supasa P, Liu C, Mentzer AJ, Ginn HM, et al. Evidence of escape of SARS-CoV-2 variant B.1.351 from natural and vaccine-induced sera. Cell. 2021; 184: 2348-2361.

[86] Vasileiou E, Simpson CR, Shi T, Kerr S, Agrawal U, Akbari A, et al. Interim findings from first-dose mass COVID-19 vaccination roll-out and COVID-19 hospital admissions in Scotland: a national prospective cohort study. The Lancet. 2021; 397: 16461657. 2021.

[87] Vasileiou E, Simpson CR, Shi T, Kerr S, Agrawal U, Akbari A, et al. Interim findings from first-dose mass COVID-19 vaccination roll-out and COVID-19 hospital admissions in Scotland: a national prospective cohort study. The Lancet. 2021; 397: 16461657.

[88] Moderna COVID-19 vaccine retains neutralizing activity against emerging variants first identified in the U.K. and the republic of South Africa [press release]. Press release Moderna. 2021.

[89] GSK and CureVac to develop next generation mRNA COVID19 vaccines [press release]. Press release GSK 2021.

[90] van Doremalen N, Purushotham JN, Schulz JE, Holbrook MG, Bushmaker T, Carmody A, et al. Intranasal ChAdOx1 nCoV19/AZD1222 vaccination reduces viral shedding after SARSCoV-2 D614G challenge in preclinical models. Science Translational Medicine. 2021; 13: eabh0755.

[91] Park J-G, Oladunni FS, Rohaim MA, Whittingham-Dowd J, Tollitt J, Hodges MDJ, et al. Immunogenicity and protective efficacy of an intranasal live-attenuated vaccine against SARSCoV-2. Science. 2021; 24: 102941.

Keywords: Immunogenicity; Safety; SARS-CoV-2; Vaccines

Send correspondence to: Chit Laa Poh, Centre for Virus and Vaccine Research, School of Medical and Life Sciences, Sunway University, Bandar Sunway, 47500 Subang Jaya, Selangor, Malaysia, E-mail: pohcl@sunway.edu.my $\dagger$ These authors contributed equally. 